\title{
COMPARATIVE EVALUATION OF MICROHARDNESS AND COMPRESSIVE STRENGTH OF CENTION N, BULK FILL RESIN COMPOSITE AND GLASS IONOMER CEMENT
}

\author{
Rehab Khalil Safy* and Emad Abdelfatah Aboalazm**
}

\begin{abstract}
Objective: Evaluation of microhardness and compressive strength of Cention $\mathrm{N}$ in comparison to nanohybrid bulk fill resin composite and glass ionomer cement (GIC).

Methodology: A total of 30 specimens were prepared for microhardness evaluation, divided into three key groups of ten specimens each depending on the type of bulk fill restorative material used; Cention N, Tetric Evo Ceram bulk fill resin composite and Fuji IX GP groups. Specimens were prepared using a specially constructed $4 \mathrm{~mm}$ thickness cylindrical Teflon mold with a diameter of $6 \mathrm{~mm}$. All specimens were stored in distilled water at room temperature for 24 hours then subjected for Vickers microhardness tester. Assessment of compressive strength of the tested restorative materials necessitates fabrication of 30 specimens with a diameter of $3 \mathrm{~mm}$ and $6 \mathrm{~mm}$ thickness (ten specimens each). Universal testing machine was used for evaluation of compressive strength of all tested materials. Results obtained were subjected to one-way ANOVA and Tukey's HSD test (P values of 0.05$)$.
\end{abstract}

Results: Both microhardness and compressive strength tests results showed that there was no significant difference between Tetric EVO Ceram and Cention N $(p<0.001)$, meanwhile both of them are significantly higher than Fugi IX GP.

Conclusions: Under the limitation of the current study, the bioactive composite Cention $\mathrm{N}$ is a promising bulk fill resin composite restoration in the posterior region in terms of tested mechanical properties.

KEY WORDS: Cention N, bulk fill resin composite, GIC, microhardness, compressive strength.

\section{INTRODUCTION}

Numerous direct restorative materials are marketed to the contemporary dental practice.
Therefore, properties such as adhesion to the tooth structure, adequate strength of the materials, resistance to recurrent caries and ease of application, should be considered when selecting restorative

\footnotetext{
* Associate Professor, Restorative Dentistry, Suez Canal University, Egypt

** Associate Professor, Restorative Dentistry, Egyptian Russian University, Egypt
} 
materials ${ }^{[1]}$. Over years, restorative materials have evolved exponentially, taking into account the most commonly used restorative materials and each has its advantages and drawbacks that should be weighed meticulously before selecting a restorative material ${ }^{[2]}$. Since 1972, glass ionomer cements (GIC) have been commercially available as a restorative material. Specific properties such as fluoride release, adherence to mineralized dental tissues and ease of application as a bulk filling material make it an effective material for dental restoration ${ }^{[3]}$. However, multiple disadvantages were reported for GIC such as poor mechanical properties and low esthetic value thereby alternative restorative materials have been investigated ${ }^{[4]}$. Along with modern adhesives, the emergence of innovative resin composite restorative technologies has brought tremendous benefits especially in terms of aesthetics and moving towards minimally invasive dental practice. Nevertheless, they may be viewed as costly, technologically sensitive and time consuming incremental technique ${ }^{[5]}$.

The need for quicker and simpler restorative therapy has contributed to the development of bulk filled resin based composites that can be placed in single incremental layer ranging from 4 to $6 \mathrm{~mm}$ ${ }^{[6,7]}$. The ambiguity of sufficient curing depth is still significantly influencing the rapid restorative procedure with light cured bulk fill materials ${ }^{[8]}$. Therefore, a lot of dual curing resin based composites which are suitable for bulk filling operation were recently as an attempt to give a durable, aesthetic, easy filling content.

Furthermore, innovation of some of these materials focuses on development of bioactive properties such as releasing Ions that neutralize acid to avoid demineralization. One approach of this trend utilized alkaline fillers embedded in a methacrylate resin matrix and marketed as a restorative bioactive material known as Alkasites. This category of restorations is based on self-cured powder/liquid resin based composite with optional additional light curing ${ }^{[9]}$.
According to the claims of the manufacturer these newly introduced material releases fluoride, calcium and hydroxide ions. While clinical trials will provide the ultimate proof of Cention N's clinical success as a dental restoration, preliminary research on such a material should be carried out in vitro in order to determine its biocompatibility and durability. As the restorative material's adequate microhardness and high compressive strength are essential parameters to be deemed for adequate durability of the material, the objective of the current study was to investigate the microhardness and compressive strength of Cention $\mathrm{N}$ in comparison to nanohybrid bulk fill resin composite and GIC in order to select a suitable restorative material for teeth restoration.

\section{MATERIALS AND METHODS}

Tested materials and their description, composition, lot number and manufacturer's information are displayed in Table 1.

\section{Microhardness test}

A total of 30 specimens were prepared by the same investigator for microhardness assessment, distributed into three key groups of ten specimens each depending on utilized kind of restorative material. Specimens were prepared using a specially constructed $4 \mathrm{~mm}$ thickness cylindrical Teflon mold with a diameter of $6 \mathrm{~mm}^{[10]}$.

Preparation of Cention N specimens' was achieved through manual mixing of two measuring spoons of powder and 2 drops of Cention $\mathrm{N}$ liquid on mixing pad to a smooth consistency using a plastic Spatula. Half the powder was blended with the liquid until it was fully wet and the remaining powder was then mixed in limited amounts where the mixing time not more than one minute. The Teflon mold was mounted on a glass slide covered with a Mylar strip then the paste was placed in the mold as one increment with Teflon coated instrument (Aesculap, Germany). The paste surface was covered with another Mylar strip and pressed to a flat surface and light cured for $20 \mathrm{sec}$ using the Elipar Free Light 2 curing device (3M ESPE, St. Paul, MN, USA) 
TABLE (1) Materials, description, composition, lot number and manufacturers.

\begin{tabular}{|c|c|c|c|c|}
\hline Materials & Description & Composition & Lot number & Manufacture \\
\hline $\begin{array}{l}\text { Tetric Evo } \\
\text { Ceram }\end{array}$ & $\begin{array}{l}\text { Nano-hybrid bulk } \\
\text { fill resin composite, } \\
\text { shade A2. }\end{array}$ & $\begin{array}{l}\text { Bis-GMA, Bis-EMA and UDMA. filler content } \\
\text { of approximately } 61 \% \text { (vol.) (barium aluminium } \\
\text { silicate glass, } 17 \% \text { Isofillers“, ytterbium fluoride } \\
\text { and spherical mixed oxide). }\end{array}$ & S08629 & \multirow{2}{*}{$\begin{array}{c}\text { Ivoclar Vivadent, } \\
\text { Schaan, } \\
\text { Liechtenstein. } \\
\text { https://www. } \\
\text { ivoclarvivadent.com/ } \\
\text { en/education/icde- } \\
\text { liechtenstein }\end{array}$} \\
\hline Cention N & $\begin{array}{l}\text { Alkasite bulk fill resin } \\
\text { composite, shade A2. }\end{array}$ & $\begin{array}{l}\text { Powder: filler content of approximately } 57.6 \% \\
\text { (vol.) (calcium fluoro-silicate glass, barium } \\
\text { glass, calcium-barium-aluminium fluoro-silicate } \\
\text { glass, iso-fillers, ytterbium trifluoride), initiators } \\
\text { and pigments. Liquid: contains dimethacrylates, } \\
\text { initiators, stabilizers, additives and mint flavor. }\end{array}$ & W44058 & \\
\hline $\begin{array}{l}\text { Fuji IX } \\
\text { GP }\end{array}$ & $\begin{array}{l}\text { Radiopaque Posterior } \\
\text { Glass Ionomer } \\
\text { Restorative Cement. }\end{array}$ & $\begin{array}{l}\text { Powder: aluminosilicate glass, polyacrylic acid } \\
\text { Liquid: polyacrylic acid, distilled water. }\end{array}$ & 1604121 & $\begin{array}{c}\text { GC, Tokyo, Japan. } \\
\text { https://www.gc-dental. } \\
\text { com/ }\end{array}$ \\
\hline
\end{tabular}

Bis-GMA, bisphenol A diglycidyl methacrylate; Bis-EMA, bisphenol A polyethylene glycol dietherdimethacrylat; UDMA, urethane dimethacrylate.

at an intensity of $12000 \mathrm{~mW} / \mathrm{cm}^{2}$ according to the manufacturer's instructions. The same technique was followed for preparation of the nanohybrid bulk fill resin composite specimens. Tetric Evo Ceram bulk fill resin composite material was packed as a bulk using Teflon coated instrument within the mold as mentioned for Cention $\mathrm{N}$ specimens. A carver was then used to extract the flushed-out excess material then specimens were gently cured for $20 \mathrm{sec}$. in accordance to the manufacturer's instructions

Fuji IX specimens were prepared through applying two measuring spoons of powder and 2 drops of the material's liquid to a mixing pad and manually mixing them to a smooth consistency. The liquid was blended until well wet with half the powder and then the remaining powder was added in small amounts where the mixing time was not more than $30 \mathrm{sec}$. as recommended by the manufacturer. Then, the paste was added as previously mentioned in the mold and permitted to be set for 10 minutes prior to removing the strip. After setting of the GIC, a final coat of GC Fuji varnish (GC, Tokyo, Japan) was painted to the surface and light cured for 20 sec. All specimens were cleaned in an ultrasonic for 10 minutes in cleaning device (Cristo'foli, Campo Mourao, Brazil), numbered and stored at room temperature in a light-proof bottle for 24 hours in distilled water to complete their polymerization without any effect from transient light ${ }^{[11]}$.

A microhardness testing machine (HMG-G; Shimadzu, Kyoto, Japan) was used to measure the Vickers hardness number (VHN) of each specimen. The microhardness test was conducted using a diamond indenter with a $100 \mathrm{gm}$ load for $10 \mathrm{sec}$. Three indentations evenly spaced over a circle and not closer than $1 \mathrm{~mm}$ to the adjacent indentation or margin of the specimen were created in each specimen at top surface and Vickers microhardness number means were calculated by the following equation ${ }^{[12]}$ :

\section{VHN: $\mathrm{HV}=1.854 \mathrm{P} / \mathrm{d}^{2}$}

Where, HV was Vickers hardness in $\mathrm{Kgf} / \mathrm{mm}^{2}$, $\mathrm{P}$ was the load applied in Kgf and d was the length of the diagonals in $\mathrm{mm}$ and 1.854 was a constant number. 


\section{Compressive strength test}

According to the American Dental Association (ADA), ten cylindrical specimens of each checked restorative material were prepared by the same investigator according to 27 requirements (3 $\mathrm{mm}$ diameter $\times 6 \mathrm{~mm}$ height) by using specially constructed flat Teflon mold ${ }^{[13]}$. All specimens were prepared, cured and stored as described before in the microhardness test specimens' preparation following the manufacturer's instructions. Compressive strength of all specimens was evaluated using universal testing machine (Instron, Model 3345 England) at loading mode of 5000 Newton load cell with a $1 \mathrm{~mm} / \mathrm{min}$. Failure manifested by the first crack sound initiation and confirmed by a sudden drop in the load-deflection curve and recorded with Blue Hill Instron computer software (Blue Hill, Instron). The compressive strength was calculated by using the equation ${ }^{[14]}: \mathbf{F}=\mathbf{P} / \mathbf{A}$, where $\mathrm{F}$ is compressive strength of specimen in Mega Pascal, $\mathrm{P}$ is the maximum applied load by newton and $\mathrm{A}$ is the cross-sectional area estimated in $\mathrm{mm}^{2}$.

\section{Statistical analysis}

One-Way ANOVA was used to compare between the tested groups followed by Tukey's HSD test for multiple comparison. The analysis was done using IBM SPSS (version 25, Armonk, NY, USA) and P values of 0.05 were considered to be statistically significant.

\section{RESULTS}

Microhardness results revealed that the highest mean value was recorded for Tetric EVO Ceram bulk fill $(81.51 \pm 2.4)$ followed by Cention $\mathrm{N}$ (78.26 \pm 4.66$)$, meanwhile the lowest mean value was recorded for Fugi IX GP (38.52 \pm 3.14$)$. Regarding compressive strength test the results showed that the highest mean value was recorded for Tetric EVO Ceram bulk fill (338.77 \pm 16.09$)$ followed by Cention $\mathrm{N}(331.17 \pm 11.31)$, meanwhile the lowest mean value was recorded for Fugi IX GP (211.69 \pm 5.53$)$. Both Microhardness and compressive strength tests results showed that there was no significant difference between Tetric EVO Ceram bulk fill and Cention $\mathrm{N}(p<0.001)$, meanwhile both of them are significantly higher than Fugi IX GP (Table 2 \& Figure 1).

TABLE (2): Compressive strength and microhardness means values of all groups

\begin{tabular}{|c|c|c|c|}
\hline & $\begin{array}{c}\text { Tetric Evo } \\
\text { ceram }^{\circledR}\end{array}$ & Cention $^{\circledR} \mathbf{N}$ & Fugi IX GP \\
\hline Microhardness & $81.51^{\mathrm{a}} \pm 2.4$ & $78.26^{\mathrm{a}} \pm 4.66$ & $38.52^{\mathrm{b}} \pm 3.14$ \\
\hline $\begin{array}{c}\text { Compressive } \\
\text { strength }\end{array}$ & $338.77^{\mathrm{a}} \pm 16.09$ & $331.17^{\mathrm{a}} \pm 11.31$ & $211.69^{\mathrm{b}} \pm 5.53$ \\
\hline
\end{tabular}

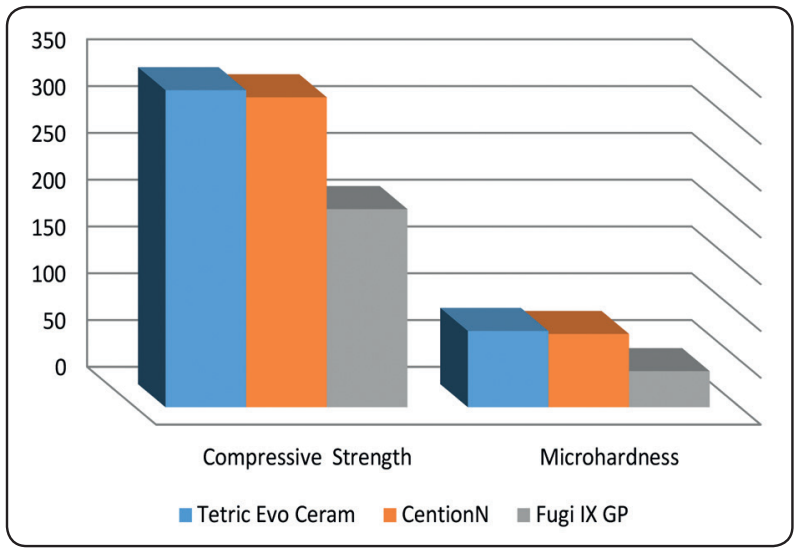

Fig. (1) Bar chart of compressive strength and microhardness means values of all tested groups.

\section{DISCUSSION}

The quality and quantity of the ions released from restorative materials, as well as the physical and mechanical properties, are critical for patients with a high risk level of caries ${ }^{[15]}$. Fluoride releasing materials have shown low plaque formation as compared to other dental materials ${ }^{[16]}$. While dental materials releasing fluoride are the correct choice when preventing caries, their low mechanical properties are still a major problem ${ }^{[17]}$. The results of the current study showed that GIC had lower mechanical values compared to both composite resin materials tested, which were anticipated due to the 
inherent structure of the GIC content. As a primary concern for dental practitioners is the achievement of predictable and reliable, bioactive and time saving direct posterior restoration, restoration of teeth with a bulk fill restorative material is beneficial for both the patient and the dental practitioner ${ }^{[18]}$. Cention $\mathrm{N}$ (Alkasite) has recently been introduced as a bioactive tooth colored bulk fill resin composite material suitable for restoration of class I, II and $\mathrm{V}$, but limited number of studies has focused on its mechanical properties ${ }^{[9]}$. In the current research, microhardness and compressive strength tests were utilized to investigate the clinical performance of dental restorative materials tested as they are simple to apply and provide reliable data ${ }^{[19]}$. Results of this study revealed that Tetric Evo Ceram bulk fill resin composite showed the highest microhardness and compressive strength mean values with no significant difference with Cention N. Meanwhile both of them were significantly higher than Fuji IX GP.

It is worth noting that several compositions' related factors have been identified to affect the resin composite restorative material surface microhardness ${ }^{[20]}$. Mass fractions ${ }^{[21,22,23]}$, size and distribution of filler particles have been reported to have a major impact on certain physical and mechanical properties, including surface microhardness $\left.{ }^{[24} 25\right]$. It was also reported that other factors like particle shape and density, type and ratio of monomer, degree of crosslinking of polymers and photoinitiators seem to have a major impact on surface microhardness ${ }^{[25,26]}$. The insignificantly higher mean microhardness values of the Tetric Evo Ceram bulk fill resin composite relative to Cention $\mathrm{N}$ could therefore be clarified by approximately equivalent reduced particle dimensions and a broader distribution of size $(0.1 \mu \mathrm{m}-0.7 \mu \mathrm{m}, 0.4$ $\mu \mathrm{m}-0.7 \mu \mathrm{m})$ respectively. Therefore, adequate microhardness and high polishing ability could be expected from both of them.

Regarding compressive strength test, the highest mean value was recorded for Tetric Evo Ceram bulk fill resin composite. This result could be attributed to its slightly higher filler load which is around $61 \%$ (vol.) compared to $57.6 \%$ in Cention N. Nevertheless, the insignificant difference between them could be attributed to the existence of a highly cross-linked monomer network, using a stable, effective self-cure initiator and shrinkage stress reliever in Cention $\mathrm{N}$ material, resulting in high degree of polymerization and proper mechanical properties ${ }^{[27,28,29]}$. It should also be noted that the spherical shape of Cention $\mathrm{N}$ filler particles allows an increased filler load and increases their compressive strength, as mechanical stresses appear to focus on the angles and protuberances of the filler particles, which is not the scenario in Tetric Evo Ceram bulk fill resin composite as it characterized by irregular shaped filler particles ${ }^{[30]}$.

\section{CONCLUSIONS}

Under the limitation of the current study, Cention $\mathrm{N}$ is a promising bioactive bulk fill resin composite restoration in the posterior region in terms of tested mechanical properties. Even so, in clinical scenarios, further study of the material is necessary to evaluate its preference over other products.

\section{REFERENCES}

1. Abraham D, Thomas AM. A comparative evaluation of microleakage of glass ionomer cement and chitosan modified glass ionomer cement. An in vitro study. Int J Clin Pediatr Dent. 2014; 7(1):6-10.

2. Jayanthi N, Vinod V. Comparative evaluation of compressive strength and flexural strength of conventional core materials with nanohybrid composite resin core material an in vitro study. J Indian Prosthodont Soc. 2013; 13(3):281-289.

3. Cepowicz E., Kolada G, Zalewska A, Pawińska M, Leszczyńska K. Antibacterial activity of selected glass ionomer cements. Postepy Hig Med Dosw 2014;68:23-28.

4. Chalissery VP, Marwah N. Study of the Mechanical Properties of the Novel Zirconia - reinforced Glass Ionomer Cement. J Contemp Dent Pract. 2016 May;17(5):394-398.

5. Parolia A, Adhauliya N, de Moraes Porto IC. comparative evaluation of microleakage around class $\mathrm{V}$ cavities 
restored with different tooth colored restorative materials. Oral Health Dent Manag. 2014;13(1):120-126.

6. Finan L, Palin W, Moskwa N, McGinley E, Garry J P. The influence of irradiation potential on the degree of conversion and mechanical properties of two bulk-fill flowable RBC base materials. Dent Mater. 2013; 29(8): 906-912.

7. Alrahlah, A, Silikas, N, Watts, D.C. Post-cure depth of cure of bulk fill dental resin-composites. Dent. Mater. 2014; 30:149-154.

8. Tarle Z, Attin T, Marovic D, Andermatt L, Ristic $M$, Tauböck T. Influence of irradiation time on subsurface degree of conversion and microhardness of high-viscosity bulk-fill resin composites. Clin. Oral Investig. 2015; 19; 831-840.

9. Todd, J C. Scientific Documentation: Cention N; IvoclarVivadent Press: Schaan, Liechtenstein, 2016; pp. 1-58.

10. Ajaj RA. Relative microhardness and flexural strength of different bulk fill resin composite restorative materials. J Am Sci. 2015; 11(7):155-9.

11. Erdemir, U, Yildiz, E, Eren, M. Surface hardness evaluation of different composite resin materials: influence of sports and energy drinks immersion after a short-term period. Journal of Applied Oral Science, 2013; 21(2), 124131.

12. Karen V Ayub , Gildo C Santos Jr, Amin S Rizkalla, Richard Bohay, Luis Fernando Pegoraro, José H Rubo, M Jacinta M C Santos. Effect of preheating on microhardness and viscosity of 4 resin composites. J Can Dent Assoc. 2014, 80 (4), 191-196.

13. Didem A, Gözde Y, Nurhan O. Comparative mechanical properties of bulk-fill resins. Open Journal of Composite Materials, 2014; 4: 117-121.

14. Harish B, Hanumesh B, Siddesh T, Siddhalingesh B. An experimental investigation on partial replacement of cement by glass powder in concrete. International Research $\mathrm{J}$ of Engineering and Technology 2016 ; 03 (10), 2395 -0056 .

15. Mann J, Sharma S, Maurya S and Suman A. Cention N: A Review article. Int J Curr Res 2018 May;10(5):6911169112.

16. Naik R, Dodamani A, Khairnar M, Jadhav H, Deshmukh M. Comparative assessment of antibacterial activity of different glass ionomer cements on cariogenic bacteria. Restor Dent Endod. 2016 Nov; 41(4): 278-282.

17. Gordan V, Mondragon, E Watson RE, Garvan C, Mjör I. A clinical evaluation of a self-etching primer and a giomer restorative material. J of American Dent Assoc.2007; 138.5: 621-627.
18. Didem A, Gozde Y, Nurhan O. Comparative mechanical properties of bulk-fill resins. OJCM 2014; 4:117 - 121.

19. Meenakumari C, Manohar Bhat K, Rahul Bansal. Evaluation of mechanical properties of newer nanoposterior restorative resin composites: An in vitro study. Contemp Clin Dent. 2018 Jun;9(Suppl 1):S142-S146.

20. Okada K, Tosaki S, Hirota K, Hume WR. Surface hardness change of restorative filling materials stored in saliva. Dent Mater 2001; 17:34-9.

21. Xinxuan Zhou Xiaoyu Huang Mingyun Li Xian Peng Suping Wang Xuedong Zhou Lei Cheng. Development and status of resin composite as dental restorative materials. J. Appl. Polym. Sci. 2019; 48180

22. Jack L. Ferracane, Carmem S. Pfeifer, Thomas J. Hilton. Microstructural features of current resin composite materials. Curr Oral Health Rep. 2014; 1:205-212

23. Bocion K, Szczesio A, Krasowski M, Sokolowski M. The influence of filler amount on selected properties of new experimental resin dental composite. Open Chem., 2018; 16: 905-911

24. Parag K. Shah and Jeffrey W. Stansbury. Role of filler and functional group conversion in the evolution of properties in polymeric dental restoratives, Dent Mater. 2014 May ; 30(5): 586-593.

25. Abed YA, Sabry H. A., Alrobeigy N.A. Degree of conversion and surface hardness of bulk-fill composite versus incremental-fill composite. Tanta Dent J. 2015;12. 71-80.

26. Camila Sabatini. Comparative study of surface microhardness of methacrylate-based composite resins polymerized with light-emitting diodes and halogen, European Journal of Dentistry, 2013; Jul-Sep.7, 3.

27. Samanta, S., Das, U.K., Mitra, A. Comparison of microleakage in class $\mathrm{V}$ cavity restored with flowable composite resin, glass ionomer cement and Cention N. Imp J Interdiscip Res 2017; 8(3): 180-83.

28. Mazumdar, P., Das, A., Das, U.K. Comparative evaluation of microleakage of three different direct restorative materials (silver amalgam, glass ionomer cement, cention $\mathrm{N}$ in Class II restorations using stereomicroscope: an in vitro study. Ind. J. Dent. Res. 2019; 30, 277.

29. Paromita Mazumdar P, Abiskrita Das, Mandal D. Comparative evaluation of bond strength of composite resin $\&$ cention $\mathrm{n}$ to enamel and dentin with and without etching under universal testing machine. University J Dent Scie 2018;4(3):1-6.

30. Scientific Documentation Tetric EvoCeram ${ }^{\circledR}$ Bulk Fil; Ivoclar-Vivadent Press: Schaan, Liechtenstein, 2014; pp. $1-42$. 